\title{
Wake-up stroke: clinical characteristics, imaging findings, and treatment option - an update
}

\section{Leander Rimmele and Götz Thomalla*}

Klinik und Poliklinik für Neurologie, Kopf- und Neurozentrum, Universitätsklinikum Hamburg-Eppendorf, Hamburg, Germany

\section{Edited by:}

Hanne Christensen, Bispebjerg

University Hospital, Denmark

\section{Reviewed by:}

Steven R. Levine, SUNY Downstate

Medical Center, USA

Inger Havsteen, Copenhagen

University Hospital Bispebjerg,

Denmark

\section{*Correspondence:}

Götz Thomalla, Klinik und Poliklinik für Neurologie, Kopf- und Neurozentrum, Universitätsklinikum

Hamburg-Eppendorf, Martinistr. 52, 20246 Hamburg, Germany

e-mail: thomalla@uke.de

\begin{abstract}
About $25 \%$ of all strokes occur during sleep, i.e., without knowledge of exact time of symptom onset. According to licensing criteria, this large group of patients is excluded from treatment with received tissue-plasminogen activator, the only specific stroke treatment proven effective in large randomized trials. This paper reviews clinical and imaging characteristics of wake-up stroke and gives an update on treatment options for these patients. From clinical and imaging studies, there is evidence suggesting that many wakeup strokes occur close to awakening and thus, patients might be within the approved time-window of thrombolysis when presenting to the emergency department. Several imaging approaches are suggested to identify wake-up stroke patients likely to benefit from thrombolysis, including non-contrast CT, CT-perfusion, penumbral MRI, and the recent concept of diffusion weighted imaging-fluid attenuated inversion recovery (DWI-FLAIR). A number of small case series and observational studies report results of thrombolysis in wake-up stroke, and no safety concerns have occurred, while conclusions on efficacy cannot be drawn from these studies. To this end, there are ongoing clinical trials enrolling wake-up stroke patients based on imaging findings, i.e., the DWI-FLAIR-mismatch (WAKEUP) or penumbral imaging (EXTEND). The results of these trials will provide evidence to guide thrombolysis in wake-up stroke and thus, expand treatment options for this large group of stroke patients.
\end{abstract}

Keywords: wake-up stroke, acute ischemic stroke, thrombolysis, computed tomography, magnetic resonance imaging, fluid attenuated reversion recovery, DWI-FLAIR-mismatch

\section{METHODS}

The literature used in this review was searched in PUBMED and MEDLINE (1977-2013 October) using the following key words "wake-up stroke," "stroke on awakening," "stroke of unknown symptom onset," "thrombolysis," "diffusion weighted imaging," and "fluid attenuated inversion recovery (FLAIR)." The selection was made by the authors evaluating clinical relevance, currentness, and methodical correctness. Our purpose was not to give a general overview of the current state of literature concerning thrombolysis in wake-up stroke in general, but to emphasize the possibilities of treatment for wake-up stroke on the basis of current literature. Therefore, we have done no systematic literature review but one focused on our demand.

\section{STROKE AND STROKE THROMBOLYSIS}

Patients waking-up with symptoms of stroke represent a specific subgroup of stroke patients. In general, stroke is the second most common single cause of death and the most frequent cause of permanent disability in industrialized countries. Based on WHO estimates about 15 million people suffer from stroke each year of whom five million are left permanently disabled (1). As a consequence, stroke carries an enormous social and economic burden both for the individual patients as for society at large. In the EU stroke accounts for just over 500,000 deaths each year with just around 1 in 10 men (9\%) and 1 in 8 women (12\%) dying from stroke (2).
The demonstration of efficacy and safety of treatment with intravenous tissue plasminogen activator (IV-tPA) (3) has ended an age of therapeutic nihilism and revolutionized stroke care. Together with the establishment of the stroke-unit concept, thrombolysis has motivated the implementation of specialized acute stroke treatment in most developed countries.

In ischemic stroke, the acute occlusion of a brain vessel leads to hypoperfusion of the downstream brain areas resulting in an insufficient supply with oxygen. Within seconds the functional metabolism of brain cells breaks down, and depending on the degree and duration of ischemia, the affected brain areas decay. Thrombolysis aims to reperfuse the brain vessel occlusion by dissolution of the clot. In acute stroke, thrombolysis was proven effective in two randomized controlled trials resulting in a marked increase of the number of patients with a favorable outcome after stroke $(3,4)$. In large observational trials, this effect was reproduced in the clinical practice (5), and thrombolysis has become a keystone of acute stroke treatment. However, thrombolysis was only proven effective in patients treated within $4.5 \mathrm{~h}$ of symptom onset, and is only recommended for patients to be treated within this time-window.

\section{WAKE-UP STROKE}

In a large number of stroke patients, the time point of symptom onset is not known. About $20-25 \%$ of stroke patients realize stroke symptoms after waking-up from sleep (6-9) (Table 1). 
This subgroup of stroke patients ("wake-up strokes") differs from stroke patients who suffer from stroke while being awake and pose a specific challenge to stroke physicians. The most relevant difference between both groups is the fact that in wake-up stroke patients, the exact time point of symptom onset is unknown. As a result, according to approval criteria and guideline recommendations, this large group of patients is excluded from thrombolysis $(9,10)$, thus excluding patients from the only approved specific treatment of acute stroke with proven safety and efficacy.

Within the past years, however, wake-up stroke has come into focus of research activities. Observational studies have brought insights into clinical and imaging characteristics of wake-up stroke; new approaches to guide treatment in wake-up stroke patients have been suggested. Finally, clinical trials are underway testing intravenous thrombolysis in patients with unknown time of symptom onset including wake-up stroke. We will give an update of the recent insights on wake-up stroke and ongoing developments that are likely to improve the treatment of these patients in the near future.

\section{CLINICAL AND IMAGING CHARACTERISTICS OF WAKE-UP STROKE}

There are observations that point toward strokes during sleep being more severe (15) and having a worse clinical outcome (12). In a recent large analysis of wake-up-stroke as compared to stroke while awake, a smaller initial severity for wake-up-stroke with deterioration to comparable mortality and morbidity was shown (14). Especially, the secondary deterioration underlines the potential responsiveness of wake-up stroke for therapy. In addition, further clinical and imaging observations suggest that in a large number of patients waking-up with stroke symptoms strokes may have occurred in the early morning hours so that they might still be eligible for thrombolysis. There are studies reporting comparable frequency of early ischemic signs on CT (EICs) in wake-up stroke patients as compared to patients studied by CT within 3 (16) or $6 \mathrm{~h}$ of symptom recognition (17). Additionally, the equal developmental time pattern of EICs in patients with known and unknown onset in a follow-up from $3 \mathrm{~h}$ after recognizing the symptoms to 3 months supports the presumption that wake-up strokes occur close to awakening (18). An MRI-based study reported a similar proportion of wake-up stroke patients showing a perfusion-diffusion-mismatch as compared to patients within $3 \mathrm{~h}$ of symptom onset (11). A similar observation was made for the detection of "tissue at risk" by perfusion CT in wake-up stroke patients (18). Together these findings suggest that a large number of patients with wake-up stroke might still be within a time-window for thrombolysis when reaching the hospital.

\section{IMAGING APPROACHES TO GUIDE TREATMENT IN WAKE-UP STROKE}

To identify wake-up stroke patients who may benefit from thrombolysis two imaging approaches are set in the focus of investigation. The detection of tissue at risk by penumbral imaging (perfusion-diffusion mismatch, Figure 1), and the approach of identifying stroke patients within the $4.5 \mathrm{~h}$-time-window by tissue characteristics in stroke MRI [diffusion weighted imaging (DWI)-FLAIR-mismatch]. Penumbral imaging based on DWI and
Table 1 | Incidence of wake-up stroke.

\begin{tabular}{lcc}
\hline Wake-up strokes (\%) & Total & Reference \\
\hline $100(27)$ & 364 & $(11)$ \\
$301(24)$ & 1.248 & $(8)$ \\
$349(14)$ & 2.585 & $(12)$ \\
$48(18)$ & 263 & $(13)$ \\
$273(14)^{a}(+12 \%$ "no estimation of onset") & 1.854 & $(6)$ \\
$5.152(30)$ & 17.398 & $(14)$ \\
\hline
\end{tabular}

${ }^{a}$ Of note, according to clinical in- and exclusion criteria $36 \%$ of these patients were potentially eligible for thrombolysis according to the authors.

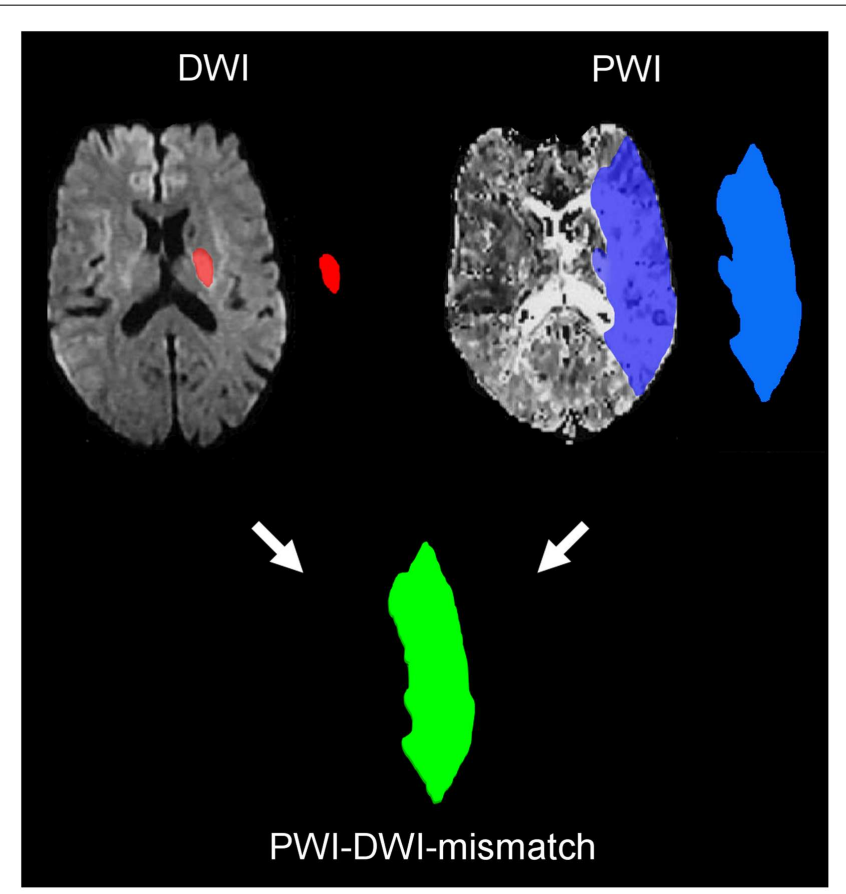

FIGURE 1 | MRI perfusion-diffusion mismatch. The small lesion on diffusion weighted imaging (DWI) represents the infarct core, while the much larger area in the time to peak map calculated from perfusion imaging (PWI) identifies the area of critically hypoperfused tissued. The mismatch between both volumes represents the tissue at risk of infraction and thus, the target tissue for reperfusion treatment.

perfusion MRI allows to determine the status of damaged tissue in acute ischemia and to distinguish irreversibly damaged one from critically hypoperfused but potentially salvageable tissue. The mismatch of these was suggested to identify tissue that is tPA-responsive beyond time-window or independent from time (19-21). In observational studies, it was shown that tissue at risk may be saved by reperfusion up to $6 \mathrm{~h}$ after symptom onset (22). Secondary analysis of randomized controlled trials with selection by penumbral imaging $(23,24)$ demonstrated a reduction of final infarct volume (25) and a clinical benefit of thrombolysis in patients with a large perfusion-diffusion mismatch with an odds ratio for good clinical response of 2.83 between desmoteplase and placebo (26). Moreover, large DWI lesion volumes were found to 
be associated with a higher risk of symptomatic intracranial hemorrhage (SICH) and poor outcome $(22,27,28)$. Thus, the exclusion of patients with very large DWI lesion volumes by MRI will likely increase the safety of MRI-based thrombolysis. The re-analysis of EPITHET and DEFUSE resulted in a more restrictive definition of the perfusion lesion $(29,30)$, which are used in the ongoing Extending the time for Thrombolysis in Emergency Neurological Deficits (EXTEND) trial (31). The detection of treatable wake-up strokes by perfusion-diffusion mismatch has been suggested (3234 ) and used in a relatively small non-randomized trial (35). In line with these considerations, the EXTEND trial will allow the randomization of patients with wake-up stroke based penumbral imaging.

The DWI-FLAIR-mismatch (Figure 2) concept refers to the time-window. There is a broad and striking evidence for the benefit of intravenous thrombolysis of ischemic stroke within $4.5 \mathrm{~h}$ $(3,4,35)$. Therefore, it was suggested to use brain imaging to determine stroke age in the case of unknown symptom onset. The chronological evolution of ischemic stroke can be characterized by MRI. A lack of cerebral blood flow with a decreased intracellular energy metabolism causes cytotoxic edema, which can be detected by a reduced apparent diffusion coefficient (ADC) on DWI within minutes of stroke $(36,37)$. During the following $1-4 \mathrm{~h}$, tissue osmolality increases, accompanied by a net increase of water $(38,39)$. This absolute increase of water content can be detected by T2-weighted MRI $(36,40)$. Thus, DWI allows an instant determination of acute ischemic lesions, but gives no evidence of further developmental changes, which may be characterized by T2. Due to artificial limitations of T2 caused by the high signal intensity of cerebrospinal fluid (CSF) with partial volume effects FLAIR is considered superior and more widely used $(41,42)$. The pattern of a visible ischemic lesion on DWI together with normal T2-weighted imaging or FLAIR is a typical finding in human stroke if imaging is performed within the first hours of stroke (43-45). These results are also well in line with data from experimental stroke, where T2wI failed to detect acute ischemia until about $2-3 \mathrm{~h}$ of stroke $(37,46,47)$.

The DWI/FLAIR-mismatch was established (48) to estimate lesion age and identify patients likely to benefit from thrombolysis. It differs from the perfusion-diffusion coefficient by revealing information about the time and not the quality of damage. Single-center studies reported of a $100 \%$ visibility of ischemic lesions after 3-6h (49-51), and the DWI-FLAIR-mismatch was shown to identify patients within $3-4.5 \mathrm{~h}$ with high specificity and positive predicted value (PPV) (48-51). These results have been confirmed in large multicenter studies (PRE-FLAIR: PREdictive value of FLAIR and DWI for the identification of acute ischemic stroke patients $\leq 3$ and $\leq 4.5 \mathrm{~h}$ of symptom onset - a multicenter study including 643 patients) (52). The specificity of the DWI-FLAIR-mismatch to identify patients within the time frame of $4.5 \mathrm{~h}$ was in this study 0.81 and the PPV 0.87 . The identification within $6 \mathrm{~h}$ showed a PPV of 0.95 in PRE-FLAIR (50), and 1 of 0.97 in a Japanese study (49). Concerning the Cochrane analysis indicating a possible beneficial effect of thrombolysis in addition with the absence of an increased risk of SICH up to $6 \mathrm{~h}$ of symptom onset $(53,54)$, these results are of paramount interest for treatment indication. Just recently, an observational study reported of a high frequency (44\%) of wake-up strokes

\section{DWI-FLAIR-mismatch}

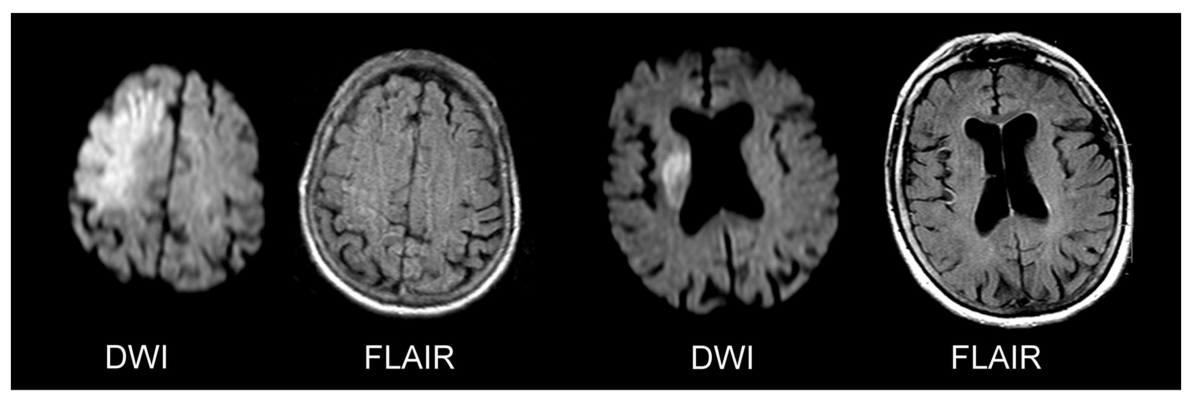

No DWI-FLAIR-mismatch

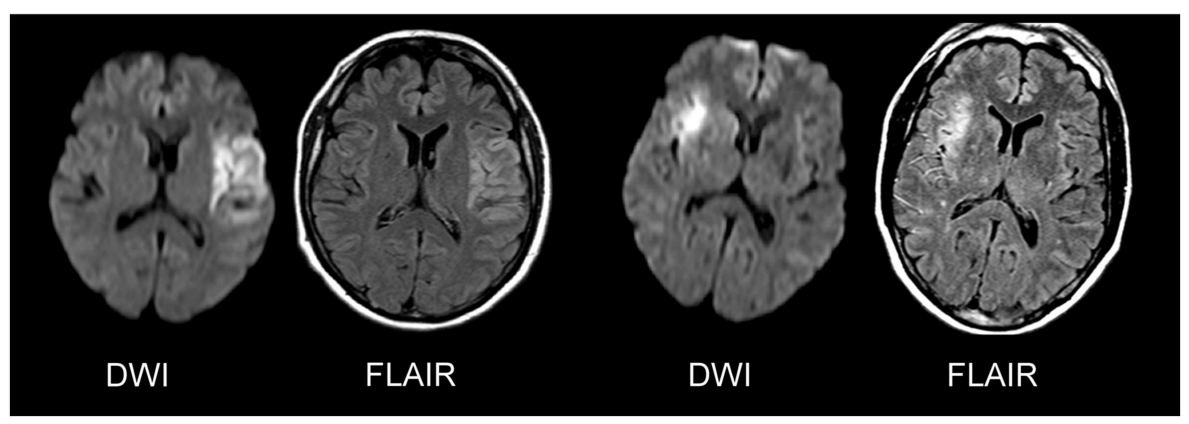

FIGURE 2 | DWI-FLAIR-mismatch. The upper row gives two examples of a clearly visible acute ischemic lesion on diffusion weighted imaging (DWI), while no marked parenchymal hyperintensity is detected on fluid attenuated inversion recovery (FLAIR) images indicating DWI-FLAIR-mismatch. In the lower row, a clear hyperintensity can be seen on FLAIR images in the area of the acute DWI lesion (no DWI-FLAIR-mismatch). 
showing a DWI-FLAIR-mismatch (55). Based on this evidence, the Efficacy and safety of MRI-based thrombolysis in wake-up stroke: a randomized, double-blind, placebo-controlled trial (WAKE-UP) will randomize wake-up stroke patients using the DWI-FLAIRmismatch as the imaging criterion to identify patients likely to benefit from thrombolysis (56).

\section{THROMBOLYSIS IN WAKE-UP STROKE: CASE REPORTS AND OBSERVATIONAL STUDIES}

Resulting from the dissatisfaction with the lack of any evidencebased treatment recommendations for patients with wake-up stroke, there is a growing number of case reports and case series, which report on thrombolysis in patients with wake-up stroke based on imaging findings (Table 2). These studies used either plain CT (50), multiparameteric CT (57-60), or multiparametric stroke MRI (32-35). In a study including 74 patients with an onset time over $4.5 \mathrm{~h}$ and 73 patients with an unknown onset no difference in eligibility and response for perfusion CT based thrombolysis was shown (59). Non-contrast CT and clinically indicated thrombolysis for wake-up ischemic stroke in over 80 years old patients was considered to be beneficial concerning the modified Ranking Scale (mRS) after 90 days compared to non-thrombolysed patients (61), and a comparison with initial and follow-up examination (mRS) after 90 days of 68 patients with wake-up ischemic stroke to 326 patients within the timewindow of $4.5 \mathrm{~h}$ showed equal results after thrombolysis indicated by non-contrast CT scan combined with clinical judgment (62). In a further single-center observational safety study 20 patients were treated with intravenous thrombolysis in the presence of an arterial occlusion on CT-A and an ASPECTS score of greater than five on baseline CT (60).

RESTORE (reperfusion therapy in unclear-onset stroke based on MRI evaluation) was an observational study in which 83 of 430 patients with an unclear onset of symptoms received tissueplasminogen activator (rt-PA), intravenously, intra-arterial, or in combination. The decision for applying this therapy was made upon a perfusion-diffusion mismatch of more than $20 \%$ and negative or subtle hyperintensities on FLAIR. The clinical outcome determined by the mRS after 3 months was in $44.6 \%$ favorable and in $28.9 \%$ excellent compared to untreated patients (35). Intracranial hemorrhage with a neurological decline was reported in $6 \%$ of the treated patents. Therefore, a distinct benefit for patients being treated with rt-PA due to estimation by MRI could be shown. Restraints of this study are the non-randomized study design, the non-quantitative measurement of FLAIR, and the relatively small number of treated patients with unknown symptom onset.

Finally, there is a single-armed observational US American study of thrombolysis with Alteplase in patients with unknown symptom onset (MR WITNESS: a Study of Intravenous Thrombolysis with Alteplase in MRI-Selected Patients, ClinicalTrials.gov. Identifier: NCT01282242). MR WITNESS will use the concept of DWI-FLAIR-mismatch to identify patients likely to respond to thrombolysis and plans to enroll 80 patients.

In summary, these studies demonstrate the feasibility of imaging guided thrombolysis in wake-up stroke patients while there was no excess in SICH and outcome appeared in large parts similar as compared to thrombolysis in patients treated within $4.5 \mathrm{~h}$ of known symptom onset. However, final conclusions to the safety

Table 2 | Trials with thrombolysis with indication set by imaging in wake-up strokes.

\begin{tabular}{|c|c|c|c|}
\hline Sample size wake-up stroke & Imaging method & Main results & Reference \\
\hline $\begin{array}{l}68 \text { Strokes with unknown onset, all received } \\
\text { IV-tPA (case-control comparison) }\end{array}$ & NECT & $\begin{array}{l}\text { Similar outcome as treatment within } 4.5 \mathrm{~h} \text { (mRS } \\
\text { after } 3 \text { months, any } \mathrm{ICH} \text {, symptomatic } \mathrm{ICH})\end{array}$ & $(61,62)$ \\
\hline $\begin{array}{l}73 \text { Strokes with unknown onset, in } 32(44 \%) \text { of } \\
\text { these IV-tPA }\end{array}$ & Perfusion CT & $\begin{array}{l}\text { No } \mathrm{SICH}, 56 \% \text { good outcome after } 3 \text { months } \\
(\mathrm{mRS}<2)\end{array}$ & (59) \\
\hline $\begin{array}{l}89 \text { Strokes with unknown onset, in } 20(22 \%) \text { of } \\
\text { these thrombolysis }\end{array}$ & NECT and CT-A/TCD & $\begin{array}{l}\text { Two asymptomatic } \mathrm{ICH} \text {, none symptomatic, two } \\
\text { died of massive infarction, two died of stroke } \\
\text { complications }\end{array}$ & (60) \\
\hline $\begin{array}{l}80 \text { Wake-up strokes, } 46 \text { received thrombolysis } \\
\text { (intra-arterial, IV-tPA, or combined) }\end{array}$ & $\begin{array}{l}\text { NCCT, CT- or } \\
\text { MRI-perfusion-diffusion mismatch }\end{array}$ & $\begin{array}{l}\text { Two symptomatic ICH, better clinical outcome } \\
\text { (mRS) and higher mortality in treated cohort }\end{array}$ & (57) \\
\hline $\begin{array}{l}43 \text { Strokes with unknown onset, } 10 \text { (22\%) } \\
\text { received IV-tPA }\end{array}$ & Perfusion-diffusion mismatch (MRI) & One asymptomatic $\mathrm{ICH}$, no symptomatic $\mathrm{ICH}$ & $(32)$ \\
\hline 32 Strokes with unclear onset & $\begin{array}{l}\text { Perfusion-diffusion mismatch and } \\
\text { FLAIR(non-quantitative) }\end{array}$ & $\begin{array}{l}\text { No difference in frequency of symptomatic ICH } \\
\text { and } 3 \text { months outcome (mRS after } 3 \text { months) to } \\
\text { treatment within } 4.5 \mathrm{~h}\end{array}$ & (33) \\
\hline $\begin{array}{l}430 \text { Strokes with unknown onset, in } 83(19.3 \%) \\
\text { of these thrombolysis ( } 10 \% \text { IV-tPA only) }\end{array}$ & $\begin{array}{l}\text { Perfusion-diffusion mismatch and } \\
\text { FLAIR(non-quantitative) }\end{array}$ & $\begin{array}{l}\text { Benefit of treatment (after } 3 \text { months: } 44.6 \% \mathrm{mRS} \\
0-2 ; 28.9 \% \text { mRS 0-1) with safe MRI-based } \\
\text { indication (symptomatic ICH in } 6 \% \text { ) }\end{array}$ & (35) \\
\hline
\end{tabular}

IV-tPA, intravenous tissue plasminogen activator; NECT, non-enhanced computed tomography; CT-A, CT-angiography; TCD, transcranial Doppler ultrasound; FLAIR, fluid attenuated reversion recovery; $\mathrm{ICH}$, intracranial hemorrhage. 
and efficacy of thrombolysis in wake-up stroke can only be drawn from randomized clinical trials.

\section{RANDOMIZED CONTROLLED CLINICAL TRIALS OF THROMBOLYSIS IN WAKE-UP STROKE}

Currently, two randomized controlled trials of intravenous thrombolysis allow the enrollment of patients with wake-up stroke: WAKE-UP and EXTEND.

EXTEND (ClinicalTrials.gov. Identifier: NCT00887328) is a randomized, multicentre, double-blinded, placebo-controlled phase III trial of intravenous thrombolysis with rt-PA in ischemic stroke patients (31). Treatment has to be initiated between $3 \mathrm{~h}$ (or $4.5 \mathrm{~h}$ depending on local practice) up to $9 \mathrm{~h}$ of symptom onset, or in case of wake-up stroke. For wake-up stroke, the midpoint between sleep onset (or last known to be normal) and time of waking-up must not exceed $9 \mathrm{~h}$. Further clinical inclusion criteria include a National Institutes of Health Stroke Scale (NIHSS) score of 4-26. Patients are studied by MRI including diffusion and perfusion MRI or CT including CT-perfusion and randomized to either treatment with placebo or Alteplase $(0.6$ or $0.9 \mathrm{mg} / \mathrm{kg}$ bodyweight based on local practice) if they show a penumbral pattern on MRI or CT. Penumbral pattern is defined by infarct core volume $<70 \mathrm{ml}$, perfusion lesion/infarct core mismatch ratio $>1.2$, and absolute mismatch $>10 \mathrm{ml}$. For definition of the perfusion lesion Tmax $>6 \mathrm{~s}$ for MRI and CT is used, while infarct core is defined using MRI diffusion imaging or CT-CBF imaging. The primary outcome measure is a favorable outcome defined by a score of $0-1$ on the mRS at day 90. EXTEND aims to enroll 400 patients in Australia and in an accompanying study in international study sites (EXTEND international). There is a European companion study under preparation (ECASS 4-EXTEND-Europe), which will only use MRI for patient enrollment.

WAKE-UP (ClinicalTrials.gov. Identifier: NCT01525290) is the first clinical trial to use the novel approach of DWI-FLAIRmismatch to prospectively identify patients for thrombolysis. WAKE-UP is an investigator-initiated, interventional, randomized, double-blind, placebo-controlled, parallel-assignment, international, multi-center efficacy, and safety study (56). The aim of WAKE-UP is to test efficacy and safety of MRI-based intravenous thrombolysis with rt-PA (Alteplase) in patients with unknown symptom onset, e.g., patients waking-up with stroke symptoms who otherwise fulfill the approval criteria for intravenous thrombolysis in acute stroke. Patients fulfilling clinical inclusion and exclusion criteria will undergo MRI including DWI and FLAIR. They will be randomized 1:1 to either treatment or placebo if MRI is indicative of lesion age of less than $4.5 \mathrm{~h}$, i.e., shows a DWIFLAIR-mismatch. Clinical inclusion criteria include age between 18 and 80 years and a disabling neurological deficit. Primary efficacy endpoint is favorable outcome defined by a score of $0-1$ on the mRS 90 days after stroke. Primary safety endpoints are Mortality and death or dependency 90 days after stroke. WAKE-UP plans to enroll 800 patients in 40-60 study sites in six European countries and has started recruitment in October 2012.

\section{CONCLUSION}

Patients waking-up with stroke symptoms represent a large group of stroke patients who are currently excluded from intravenous thrombolysis based on licensing criteria. Growing evidence from clinical and imaging studies suggests that a relevant proportion of patients with wake-up stroke might benefit from reperfusion treatment and be promising candidates for intravenous thrombolysis. Different imaging approaches have been suggested to select wake-up stroke patients for thrombolysis, including multiparametric CT and MRI. Approaches currently under investigation involve the identification of tissue at risk of infarction independent from time by penumbral imaging and the identification of patients within the approved time-window for thrombolysis by the concept of DWI-FLAIR-mismatch. Both approaches are currently tested in large randomized controlled trials. The results of these trials are expected to change clinical practice by making available effective and safe treatment for a large group of acute stroke patients currently excluded from specific acute treatment.

\section{REFERENCES}

1. Mackay J, Mensah GA. The Atlas of Heart Disease and Stroke. Geneva: World Health Organisation (2004).

2. Allender S, Scarborough P, Viv P, Rayner M, Leal JS, Luengo-Fernandez R, et al. European Cardiovascular Disease Statistics. 2008 ed. European Heart Network (2008).

3. Welch KMA, Tilley BC, Marler JR, Brott T, Lyden P, Grotta JC et al. Tissue plasminogen activator for acute ischemic stroke. The National Institute of Neurological Disorders and Stroke rt-PA Stroke Study Group. N Engl J Med (1995) 333:1581-7.

4. Hacke W, Kaste M, Bluhmki E, Brozman M, Davalos A, Guidetti D, et al. Thrombolysis with alteplase 3 to 4.5 hours after acute ischemic stroke. $N$ Engl J Med (2008) 359:1317-29. doi:10.1056/NEJMoa0804656

5. Wahlgren N, Ahmed N, Dávalos A, Ford GA, Grond M, Hacke W, et al. Thrombolysis with alteplase for acute ischaemic stroke in the Safe Implementation of Thrombolysis in Stroke-Monitoring Study (SITS-MOST): an observational study. Lancet (2007) 369:275-82. doi:10.1016/S0140-6736(07)60149-4 Erratum in 826 ,

6. Mackey J, Kleindorfer D, Sucharew H, Moomaw CJ, Kissela BM, Alwell K, et al. Population-based study of wake-up strokes. Neurology (2011) 76:1662-7. doi:10.1212/WNL.0b013e318219fb30

7. Moradiya Y, Janjua N. Presentation and outcomes of "wake-up strokes" in a large randomized stroke trial: analysis of data from the International Stroke Trial. J Stroke Cerebrovasc Dis (2012) 22:286-92. doi:10.1016/j.jstrokecerebrovasdis. 2012.07.016

8. Serena J, Davalos A, Segura T, Mostacero E, Castillo J. Stroke on awakening: looking for a more rational management. Cerebrovasc Dis (2003) 16:128-33. doi:10.1159/000070592

9. ESO. Guidelines for management of ischaemic stroke and transient ischaemic attack 2008. Cerebrovasc Dis (2008) 25:457-507. doi:10.1159/000131083

10. Jauch EC, Saver JL, Adams HP Jr, Bruno A, Connors JJ, Demaerschalk BM, et al. Guidelines for the early management of patients with acute ischemic stroke: a guideline for healthcare professionals from the American Heart Association/American Stroke Association. Stroke (2013) 44:870-947. doi:10.1161/ STR.0b013e318284056a

11. Fink JN, Kumar S, Horkan C, Linfante I, Selim MH, Caplan LR, et al. The stroke patient who woke up: clinical and radiological features, including diffusion and perfusion MRI. Stroke (2002) 33:988-93. doi:10.1161/01.STR.0000014585. 17714.67

12. Nadeau JO, Fang J, Kapral MK, Silver FL, Hill MD. Outcome after stroke upon awakening. Can J Neurol Sci (2005) 32:232-6. Available from: http: //cjns.metapress.com/content/x5vdn7l8gpytvf6e/

13. Boode B, Welzen V, Franke C, van Oostenbrugge R. Estimating the number of stroke patients eligible for thrombolytic treatment if delay could be avoided. Cerebrovasc Dis (2007) 23:294-8. doi:10.1159/000098330

14. Moradiya Y, Janjua N. Presentation and outcomes of "wake-up strokes" in a large randomized stroke trial: analysis of data from the International Stroke Trial. J Stroke Cerebrovasc Dis (2013) 22:286-92. doi:10.1016/j.jstrokecerebrovasdis. 2012.07.016 
15. Jimenez-Conde J, Ois A, Rodriguez-Campello A, Gomis M, Roquer J. Does sleep protect against ischemic stroke? Less frequent ischemic strokes but more severe ones. J Neurol (2007) 254:782-8. doi:10.1007/s00415-006-0438-y

16. Todo K, Moriwaki H, Saito K, Tanaka M, Oe H, Naritomi H. Early C.T. findings in unknown-onset and wake-up strokes. Cerebrovasc Dis (2006) 21:367-71. doi:10.1159/000091545

17. Roveri L, La Gioia S, Ghidinelli C, Anzalone N, De Filippis C, Comi G. Wakeup stroke within 3 hours of symptom awareness: imaging and clinical features compared to standard recombinant tissue plasminogen activator treated stroke. J Stroke Cerebrovasc Dis (2013) 6:703-8. doi:10.1016/j.jstrokecerebrovasdis. 2011.10.003

18. Silva GS, Lima FO, Camargo EC, Smith WS, Singhal AB, Greer DM, et al. Wakeup stroke: clinical and neuroimaging characteristics. Cerebrovasc Dis (2010) 29:336-42. [This study compared the frequency of CT-perfusion mismatch between 420 patients with known symptom onset and 131 patient with wake-up stroke and found a comparable frequency of CT-perfusion mismatch in both groups]. doi:10.1159/000278929

19. Baron JC, von Kummer R, del Zoppo GJ. Treatment of acute ischemic stroke. Challenging the concept of a rigid and universal time window. Stroke (1995) 26:2219-21. doi:10.1161/01.STR.26.12.2219

20. Hjort N, Butcher K, Davis SM, Kidwell CS, Koroshetz WJ, Rother J, et al. Magnetic resonance imaging criteria for thrombolysis in acute cerebral infarct. Stroke (2005) 36:388-97. doi:10.1161/01.STR.0000152268.47919.be

21. Kidwell CS, Alger JR, Saver JL. Beyond mismatch: evolving paradigms in imaging the ischemic penumbra with multimodal magnetic resonance imaging. Stroke (2003) 34:2729-35. doi:10.1161/01.STR.0000097608.38779.CC

22. Albers GW, Thijs VN, Wechsler L, Kemp S, Schlaug G, Skalabrin E, et al. Magnetic resonance imaging profiles predict clinical response to early reperfusion: the diffusion and perfusion imaging evaluation for understanding stroke evolution (DEFUSE) study. Ann Neurol (2006) 60:508-17. doi:10.1002/ana.20976

23. Davis SM, Donnan GA, Parsons MW, Levi C, Butcher KS, Peeters A, et al. Effects of alteplase beyond $3 \mathrm{~h}$ after stroke in the Echoplanar Imaging Thrombolytic Evaluation Trial (EPITHET): a placebo-controlled randomised trial. Lancet Neurol (2008) 7:299-309. doi:10.1016/S1474-4422(08)70044-9

24. Hacke W, Furlan AJ, Al-Rawi Y, Davalos A, Fiebach JB, Gruber F, et al. Intravenous desmoteplase in patients with acute ischaemic stroke selected by MRI perfusion-diffusion weighted imaging or perfusion CT (DIAS-2): a prospective, randomised, double-blind, placebo-controlled study. Lancet Neurol (2009) 8:141-50. doi:10.1016/S1474-4422(08)70267-9

25. Nagakane Y, Christensen S, Brekenfeld C, Ma H, Churilov L, Parsons MW, et al. EPITHET: positive result after reanalysis using baseline diffusion-weighted imaging/perfusion-weighted imaging co-registration. Stroke (2010) 42:59-64. doi:10.1161/STROKEAHA.110.580464

26. Warach S, Al-Rawi Y, Furlan AJ, Fiebach JB, Wintermark M, Lindsten A, et al. Refinement of the magnetic resonance diffusion-perfusion mismatch concept for thrombolytic patient selection: insights from the desmoteplase in acute stroke trials. Stroke (2012) 43:2313-8. doi:10.1161/STROKEAHA.111.642348

27. Singer OC, Humpich MC, Fiehler J, Albers GW, Lansberg MG, Kastrup A, et al. Risk for symptomatic intracerebral hemorrhage after thrombolysis assessed by diffusion-weighted magnetic resonance imaging. Ann Neurol (2008) 63:52-60. doi:10.1002/ana.21222

28. Parsons MW, Christensen S, McElduff P, Levi CR, Butcher KS, De Silva DA, et al. Pretreatment diffusion- and perfusion-MR lesion volumes have a crucial influence on clinical response to stroke thrombolysis. J Cereb Blood Flow Metab (2010) 30:1214-25. doi:10.1038/jcbfm.2010.3

29. Mlynash M, Lansberg MG, De Silva DA, Lee J, Christensen S, Straka M, et al. Refining the definition of the malignant profile: insights from the DEFUSEEPITHET pooled data set. Stroke (2011) 42:1270-5. doi:10.1161/STROKEAHA. 110.601609

30. Olivot JM, Mlynash M, Thijs VN, Kemp S, Lansberg MG, Wechsler L, et al. Optimal Tmax threshold for predicting penumbral tissue in acute stroke. Stroke (2009) 40:469-75. doi:10.1161/STROKEAHA.108.526954

31. Ma H, Parsons MW, Christensen S, Campbell BC, Churilov L, Connelly A, et al A multicentre, randomized, double-blinded, placebo-controlled Phase III study to investigate EXtending the time for Thrombolysis in Emergency Neurological Deficits (EXTEND). Int J Stroke (2012) 7:74-80. doi:10.1111/j.1747-4949.2011. 00730.x

32. Breuer L, Schellinger PD, Huttner HB, Halwachs R, Engelhorn T, Doerfler A, et al. Feasibility and safety of magnetic resonance imaging-based thrombolysis in patients with stroke on awakening: initial single-centre experience. Int J Stroke (2010) 5:68-73. doi:10.1111/j.1747-4949.2010.00410.x

33. Cho AH, Sohn SI, Han MK, Lee DH, Kim JS, Choi CG, et al. Safety and efficacy of MRI-based thrombolysis in unclear-onset stroke. A preliminary report. Cerebrovasc Dis (2008) 25:572-9. doi:10.1159/000132204

34. Iosif C, Oppenheim C, Trystram D, Domigo V, Meder JF. MR imaging-based decision in thrombolytic therapy for stroke on awakening: report of 2 cases. AJNR Am J Neuroradiol (2008) 29:1314-6. doi:10.3174/ajnr.A1069

35. Kang DW, Sohn SI, Hong KS, Yu KH, Hwang YH, Han MK, et al. Reperfusion therapy in unclear-onset stroke based on MRI evaluation (RESTORE): a prospective multicenter study. Stroke (2012) 43:3278-83. doi:10.1161/ STROKEAHA.112.675926

36. Hoehn-Berlage M, Eis M, Back T, Kohno K, Yamashita K. Changes of relaxation times (T1, T2) and apparent diffusion coefficient after permanent middle cerebral artery occlusion in the rat: temporal evolution, regional extent, and comparison with histology. Magn Reson Med (1995) 34:824-34. doi:10.1002/ mrm. 1910340607

37. Mintorovitch J, Moseley ME, Chileuitt L, Shimizu H, Cohen Y, Weinstein PR. Comparison of diffusion- and T2-weighted MRI for the early detection of cerebral ischemia and reperfusion in rats. Magn Reson Med (1991) 18:39-50. doi:10.1002/mrm.1910180106

38. Schuier FJ, Hossmann KA. Experimental brain infarcts in cats. II. Ischemic brain edema. Stroke (1980) 11:593-601. doi:10.1161/01.STR.11.6.593

39. Watanabe O, West CR, Bremer A. Experimental regional cerebral ischemia in the middle cerebral artery territory in primates. Part 2: effects on brain water and electrolytes in the early phase of MCA stroke. Stroke (1977) 8:71-6. doi:10.1161/01.STR.8.1.71

40. Venkatesan R, Lin W, Gurleyik K, He YY, Paczynski RP, Powers WJ, et al. Absolute measurements of water content using magnetic resonance imaging: preliminary findings in an in vivo focal ischemic rat model. Magn Reson Med (2000) 43:146-50. doi:10.1002/(SICI)1522-2594(200001)43:1<146::AID-MRM18>3. $0 . \mathrm{CO} ; 2-\mathrm{L}$

41. Brant-Zawadzki M, Atkinson D, Detrick M, Bradley WG, Scidmore G. Fluidattenuated inversion recovery (FLAIR) for assessment of cerebral infarction. Initial clinical experience in 50 patients. Stroke (1996) 27:1187-91. doi:10.1161/ 01.STR.27.7.1187

42. Noguchi K, Ogawa T, Inugami A, Fujita H, Hatazawa J, Shimosegawa E, et al. MRI of acute cerebral infarction: a comparison of FLAIR and T2-weighted fast spinecho imaging. Neuroradiology (1997) 39:406-10. doi:10.1007/s002340050433

43. Lutsep HL, Albers GW, DeCrespigny A, Kamat GN, Marks MP, Moseley ME. Clinical utility of diffusion-weighted magnetic resonance imaging in the assessment of ischemic stroke. Ann Neurol (1997) 41:574-80. doi:10.1002/ana. 410410505

44. Schlaug G, Siewert B, Benfield A, Edelman RR, Warach S. Time course of the apparent diffusion coefficient (ADC) abnormality in human stroke. Neurology (1997) 49:113-9. doi:10.1212/WNL.49.1.113

45. Sorensen AG, Buonanno FS, Gonzalez RG, Schwamm LH, Lev MH, HuangHellinger FR, et al. Hyperacute stroke: evaluation with combined multisection diffusion-weighted and hemodynamically weighted echo-planar MR imaging. Radiology (1996) 199:391-401.

46. Horikawa Y, Naruse S, Tanaka C, Hirakawa K, Nishikawa H. Proton NMR relaxation times in ischemic brain edema. Stroke (1986) 17:1149-52. doi:10.1161/01. STR.17.6.1149

47. Levy RM, Mano I, Brito A, Hosobuchi Y. NMR imaging of acute experimental cerebral ischemia: time course and pharmacologic manipulations. AJNR Am J Neuroradiol (1983) 4:238-41.

48. Thomalla G, Rossbach P, Rosenkranz M, Siemonsen S, Krutzelmann A, Fiehler J, et al. Negative fluid-attenuated inversion recovery imaging identifies acute ischemic stroke at 3 hours or less. Ann Neurol (2009) 65:724-32. doi:10.1002/ ana. 21651

49. Aoki J, Kimura K, Iguchi Y, Shibazaki K, Sakai K, Iwanaga T. FLAIR can estimate the onset time in acute ischemic stroke patients. J Neurol Sci (2010) 293:39-44. doi:10.1016/j.jns.2010.03.011

50. Ebinger M, Galinovic I, Rozanski M, Brunecker P, Endres M, Fiebach JB. Fluidattenuated inversion recovery evolution within 12 hours from stroke onset: a reliable tissue clock? Stroke (2010) 41:250-5. doi:10.1161/STROKEAHA.109. 568410

51. Petkova M, Rodrigo S, Lamy C, Oppenheim G, Touze E, Mas JL, et al. MR imaging helps predict time from symptom onset in patients with acute 
stroke: implications for patients with unknown onset time. Radiology (2010) 257:782-92. doi:10.1148/radiol.10100461

52. Thomalla G, Cheng B, Ebinger M, Hao Q, Tourdias T, Wu O, et al. DWI-FLAIR mismatch for the identification of patients with acute ischaemic stroke within $4.5 \mathrm{~h}$ of symptom onset (PRE-FLAIR): a multicentre observational study. Lancet Neurol (2011) 10:978-86. doi:10.1016/S14744422(11)70192-2

53. Lees KR, Bluhmki E, von Kummer R, Brott TG, Toni D, Grotta JC, et al. Time to treatment with intravenous alteplase and outcome in stroke: an updated pooled analysis of ECASS, ATLANTIS, NINDS, and EPITHET trials. Lancet (2010) 375:1695-703. doi:10.1016/S0140-6736(10)60491-6

54. Wardlaw JM, Murray V, Berge E, Del Zoppo GJ. Thrombolysis for acute ischaemic stroke. Cochrane Database Syst Rev (2009) (4):CD000213. doi:10. 1002/14651858.CD000213

55. Huisa BN, Liebeskind DS, Raman R, Hao Q, Meyer BC, Meyer DM, et al. Diffusion-weighted imaging-fluid attenuated inversion recovery mismatch in nocturnal stroke patients with unknown time of onset. J Stroke Cerebrovasc Dis (2012) 22:972-7. doi:10.1016/j.jstrokecerebrovasdis.2012.01.004

56. Thomalla G, Fiebach JB, Ostergaard L, Pedraza S, Thijs V, Nighoghossian N, et al. A multicenter, randomized, double-blind, placebo-controlled trial to test efficacy and safety of magnetic resonance imaging-based thrombolysis in wake-up stroke (WAKE-UP). Int J Stroke (2013). doi:10.1111/ijs.12011

57. Barreto AD, Martin-Schild S, Hallevi H, Morales MM, Abraham AT, Gonzales NR, et al. Thrombolytic therapy for patients who wake-up with stroke. Stroke (2009) 40:827-32. doi:10.1161/STROKEAHA.108.528034

58. Hellier KD, Hampton JL, Guadagno JV, Higgins NP, Antoun NM, Day DJ, et al. Perfusion CT helps decision making for thrombolysis when there is no clear time of onset. J Neurol Neurosurg Psychiatry (2006) 77:417-9. doi:10.1136/jnnp. 2005.067363

59. Cortijo E, García-Bermejo P, Calleja AI, Pérez-Fernández S, Gómez R, Del Monte $\mathrm{JM}$, et al. Intravenous thrombolysis in ischemic stroke with unknown onset using CT perfusion. Acta Neurol Scand (2013) 129:178-83. doi:10.1111/ane. 12160

60. Hill MD, Kenney C, Dzialowski I, Boulanger JM, Demchuk AM, Barber PA, et al. Tissue Window in Stroke Thrombolysis study (TWIST): a safety study. Can J Neurol Sci (2013) 40:17-20. Available from: http://cjns.metapress.com/ content/h50558454080g083/

61. Manawadu D, Bodla S, Keep J, Kalra L. Influence of age on thrombolysis outcome in wake-up stroke. Stroke (2013) 44:2898-900. doi:10.1161/STROKEAHA.113. 002273

62. Manawadu D, Bodla S, Jarosz J, Keep J, Kalra L. A case-controlled comparison of thrombolysis outcomes between wake-up and known time of onset ischemic stroke patients. Stroke (2013) 44:2226-31. doi:10.1161/STROKEAHA. 111.000757

Conflict of Interest Statement: Götz Thomalla is the coordinating investigator of WAKE-UP and receives funding from the European Union Seventh Framework Programme [FP7/2007-2013] under grant agreement no: 278276 (WAKE-UP). D. Leander Rimmele has no conflicts of interest.

Received: 11 December 2013; paper pending published: 20 December 2013; accepted: 11 March 2014; published online: 26 March 2014.

Citation: Rimmele DL and Thomalla G (2014) Wake-up stroke: clinical characteristics, imaging findings, and treatment option - an update. Front. Neurol. 5:35. doi: 10.3389/fneur.2014.00035

This article was submitted to Stroke, a section of the journal Frontiers in Neurology. Copyright $\odot 2014$ Rimmele and Thomalla. This is an open-access article distributed under the terms of the Creative Commons Attribution License (CC BY). The use, distribution or reproduction in other forums is permitted, provided the original author(s) or licensor are credited and that the original publication in this journal is cited, in accordance with accepted academic practice. No use, distribution or reproduction is permitted which does not comply with these terms. 